\title{
Rodolfo Cruz Miramontes (1931-2020)
}

El 26 de marzo de 2020 falleció en Ciudad de México el doctor Rodolfo Cruz Miramontes, fue miembro fundador del consejo editorial del Anuario Mexicano de Derecho Internacional y uno de sus colaboradores y asesores más comprometidos. Cruz Miramontes fue un jurista internacionalista excepcional, supo combinar de manera exitosa la academia (tanto como profesor como tratadista) con la práctica del derecho internacional. Como asesor participó en la negociación de varios tratados de libre comercio, experiencia que trasmitió a sus alumnos y la dejó plasmada en sus importantes obras escritas, tanto en libros como en artículos. Fue un especialista en derecho pluvial internacional, sus trabajos escritos fueron pioneros en la materia; en derecho internacional fronterizo, aprovechando su afinidad con el estado de Chihuahua, donde vivió parte de su vida; también lo fue en arbitraje internacional, del cual fue un entusiasta defensor; y del comercio internacional, en el que se desempeñó como defensor apasionado de los intereses de México, país por el cual tenía un ejemplar y notable afecto.

Personalmente, creo que el doctor Cruz Miramontes fue un hombre afable, honesto, elegante; que rechazaba toda actitud arrogante, siempre dispuesto a compartir sus conocimientos con la juventud. Él decía: "la cátedra no es nada más la información que se da en un aula, sino es la posibilidad de comunicar conocimientos fuera del aula, la enseñanza que nunca se acaba, la enseñanza que cala”.

\section{Manuel Becerra Ramírez}

* Universidad Nacional Autónoma de México, México; ORCID ID: https: / /orcid.org/00 00-0003-3957-9446, manuelbramirez5@hotmail.com. 